\title{
Levels of Complement Anaphylatoxin C5a in Pulmonary Effluent Fluid of Infants at Risk for Chronic Lung Disease and Effects of Dexamethasone Treatment
}

\author{
PETER GRONECK, MARTIN OPPERMANN. AND CIRISTIAN P. SPEER \\ Department of Pediatrics, Children's Hospital of the City of Cologne, Cologne. (iormany. P. (i.). De'partment of \\ Immunology /.M.O./ and Department of Pediatrics /C.P.S./. Liniversity of Göttingen, Göttinge'n. Germany.
}

\begin{abstract}
A number of studies have shown that increased numbers of neutrophils and macrophages are recruited into the airways during the development of chronic lung disease (CLD) in preterm infants. The objective of this study was to determine whether the anaphylatoxin $\mathrm{C5} \mathrm{a}$ is detectable in tracheobronchial aspirate fluid of infants at risk for CLD and to evaluate the possible effects of dexamethasone (Dxm) treatment. C5a/C5a(des Arg) levels were determined by a sensitive ELISA based on a neoepitope-specific $M \mathrm{Ab}$. In a prospective study, 27 infants (birth weight $881 \pm 169 \mathrm{~g}$, mean $\pm \mathrm{SD}$ ) still on mechanical ventilation at $d 10$ postnatal age with fraction of inspired oxygen $\geq 0.3$ and/or peak inspiratory pressure $\geq 16 \mathrm{~cm}$ $\mathrm{H}_{2} \mathrm{O}$ were randomly assigned to Dxm treatment at $\mathrm{d} 10$ ( $n$ $=14)$ or $\mathrm{d} 16(n=13)$. Ten mechanically ventilated infants with no respiratory disease or who had recovered from respiratory distress syndrome did not meet these criteria on d 10 and served as a control group (birth weight $928 \pm$ $126 \mathrm{~g})$. For the evaluation of Dxm therapy, the late treatment group was used as a control group for the early regimen. Compared with controls, $\mathrm{C} 5$ a concentrations were higher in infants at risk for CLD on d 10 [median (25th75th percentile): $2.40(1.13-3.38)$ versus $0.82(0.55-1.78)$ $\mu \mathrm{g} / \mathrm{L}, p<0.05]$. After Dxm, C5a concentrations decreased significantly in the early treatment group compared with pretreatment values in the late treatment group |d 15, pre Dxm 2.22 (0.98-3.92), post Dxm 0.57 (0.18-1.02) $\mu \mathrm{g} / \mathrm{L}, p$ $<0.01$ ]. C5a levels in plasma of eight infants were not affected by Dxm treatment. Our results show that increased levels of complement anaphylatoxin C5a are present in lung effluent fluid of infants at risk for CLD, and that local but not systemic levels are affected by Dxm. These findings indicate a role of $\mathrm{C} 5 \mathrm{a}$ in the recruitment of inflammatory cells into the airways of infants with CLD. (Pediatr Res 34: 586-590, 1993)
\end{abstract}

\section{Abbreviations}

RDS, respiratory distress syndrome

CLD, chronic lung disease

ARDS, adult respiratory distress syndrome

Dxm, dexamethasone

C5a, complement component $\mathbf{C 5}$ derived anaphylatoxin C5a(des $\mathrm{Arg}$ ), C5a without $\mathrm{C}$-terminal argininyl residue PBS-Tween, PBS containing $0.05 \%$ Tween 20

Received January 26, 1993; accepted June 24, 1993.

Correspondence: Peter Groneck, M.D.. Department of Pediatrics, Children's Hospital of the City of Cologne, Amsterdamer St. 59. D-50735 Cologne, Germany. Supported by a grant of Deutsche Forschungsgemeinschaft (Sp 239/3-1).
PIP, peak inspiratory pressure

$\mathrm{L} / \mathrm{S}$ ratio, lecithin to sphingomyelin ratio

There is evidence that an inflammatory reaction is involved in the pathogenesis of CLD in preterm infants. This disorder is associated with an increased amount of neutrophils and macrophages in the pulmonary effluent fluid $(1,2)$. Additionally, considerable chemotactic activity of tracheal aspirate fluid was found in infants at high risk for CLD (3), which may account for the neutrophil influx into the airways. The neutrophil is supposed to play an important role in producing increased permeability pulmonary edema (4) and mediating a prolonged lung injury by releasing proteolytic enzymes $(2,5)$ and reactive oxygen radicals (6). During the acute phase of RDS, activation of the kallikrein-system may also contribute to the inflammatory process (7).

The anaphylatoxin C5a is generated during the activation of either the classic or the alternative pathway of complement. It has numerous biologic effects: one of the most important functions is the chemotactic activity toward neutrophils and monocytes (8). There is evidence that neutrophil recruitment into the lungs is regulated by $\mathrm{C} 5 \mathrm{a}$ in ARDS (9), bacterial pneumonia (10), and cystic fibrosis (11). However, the possible role of C5a in neonates with CLD has not yet been defined.

Treatment with Dxm improves gas exchange and pulmonary mechanics in infants with CLD (12-17). These effects are apparently due to a decreased pulmonary inflammatory reaction ( 3 , $18,19)$, which affects pulmonary microvascular permeability $(18,20)$.

The objective of this study was to determine whether C5a could account for the increased chemotactic activity of lung effluent fluid in infants at risk for CLD by measuring C5a/ $\mathrm{C} 5 \mathrm{a}(\mathrm{des} \mathrm{Arg})$ levels in tracheobronchial aspirate fluid and to evaluate possible effects of Dxm treatment. In human serum, the carboxyl-terminal arginine of $\mathrm{C} 5 \mathrm{a}$ is rapidly cleaved by carboxypeptidase $\mathrm{N}$. This leads to the formation of $\mathrm{C} 5 \mathrm{a}$ (des Arg), which has reduced chemotactic activity compared with C5a. For the quantitation of both C5a and C5a(des Arg), a sensitive and highly specific enzyme immunoassay was applied (21).

\section{MATERIALS AND METHODS}

Patients and protocol. Sixty-seven preterm infants with birth weight $<1200 \mathrm{~g}$ who were consecutively admitted to the neonatal intensive care units of the Children's Hospital Cologne and the Perinatal Center at Women's Hospital, Cologne-Holweide, from June 18,1991 to June 18,1992 , were enrolled into a prospective randomized study on the effects of early versus late Dxm treat- 
ment on CLD. According to a clinical protocol, the criteria for randomization were: 1 ) ventilator dependency at a postnatal age of $10 \mathrm{~d}, 2$ ) fraction of inspired oxygen $\geq 0.3$ and/or PIP $\geq 16 \mathrm{~cm}$ $\mathrm{H}_{2} \mathrm{O}, 3$ ) no radiologic evidence of pneumonia, no clinical or laboratory signs of local and systemic infection (immature/total neutrophil ratio $<0.2$, serum C-reactive protein $<0.6 \mathrm{mg} / \mathrm{dL}$, negative blood and tracheal cultures). Eight infants died during the first $10 \mathrm{~d}$ of life. Of the remaining 59 neonates, 24 met the criteria mentioned above and were randomly assigned to treatment with Dxm on d 10 (early treatment group) or d 16 (late treatment group). Because measurements of plasma C5a levels were done only in the last three infants, five additional patients entered the study after June 18, 1992. Thus, in eight infants, levels of C5a were determined in both plasma and lung effluent fluid. The results of the $\mathrm{C} 5 \mathrm{a}$ concentrations in the respiratory fluids were nearly identical in these additional patients when compared with the original study group. Two infants of the total group were excluded from analysis because there was evidence of bacterial contamination of tracheobronchial aspirate fluid. Of the remaining 27 patients, 14 had been randomized into the early treatment group and 13 infants into the late treatment group. Ten of the 67 infants with birth weight $<1200 \mathrm{~g}$ who were still intubated at d 10 postnatal age but did not meet the ventilatory criteria noted above served as a control group for the Dxm treatment groups. The effects of Dxm were investigated within each treatment group. Furthermore, both groups were compared at $d 15$ of postnatal age, when the late treatment group served as a control group for the effects of Dxm $5 \mathrm{~d}$ after initiation of therapy in the early treatment group. Dxm was given intravenously every $12 \mathrm{~h}$ in divided doses over a period of $28 \mathrm{~d}$. The maximal dose was $0.5 \mathrm{mg} / \mathrm{kg} / \mathrm{d}$ for the first $3 \mathrm{~d}$ and $0.3 \mathrm{mg} / \mathrm{kg} /$ $\mathrm{d}$ for the next $3 \mathrm{~d}$. This dose was reduced by $10 \%$ until a dose of $0.1 \mathrm{mg}$ was reached on $\mathrm{d} 24$, which was given every second day until d 28. In 21 of 27 Dxm-treated infants, RDS was diagnosed clinically and confirmed by $\mathrm{L} / \mathrm{S}$ ratio analysis. All infants with RDS were treated with natural porcine surfactant, as previously described (22). The study was approved by the hospital ethics committee. Informed consent of the parents was obtained.

Sampling of tracheohronchial aspirate fluid. Tracheobronchial aspiration was performed in a standardized manner at least three times daily, by instillation of $0.5 \mathrm{~mL}$ of $0.9 \% \mathrm{NaCl}$ into the endotracheal tube. Suction catheters were inserted slightly beyond the distal tip of the tube, and lung and airway secretions were suctioned and collected in sterile specimen traps (Vygon, Ecouen, France). Tracheobronchial aspirate fluid was diluted with $0.9 \%$ saline to a total volume of $0.5 \mathrm{~mL}$, centrifuged at $3000 \mathrm{rpm}$ for $5 \mathrm{~min}$, and cell-free supernatants were frozen at $-30^{\circ} \mathrm{C}$ for later assay. During $24 \mathrm{~h}$, one specimen was obtained in each 8-h period. Immediately before analysis, the three samples for $1 \mathrm{~d}$ were pooled. The lung effluent fluid of all infants was cultured for microbiologic analysis twice weekly; additionally, bacterioscopic examinations were performed.

Plasma samples. For determination of C5a/C5a(des Arg) in plasma, $500 \mu \mathrm{L}$ of blood was obtained by venipuncture and was collected into a syringe containing dipotassium-EDTA. The plasma was separated from the blood cells by centrifugation (10 $\min / 1000 \times g)$ and was stored at $-30^{\circ} \mathrm{C}$ within $1 \mathrm{~h}$ after puncture.

ELISA for C5a/C5a(des Arg) quantitation. The quantitation of $C 5 \mathrm{a} / \mathrm{C} 5 \mathrm{a}$ (des Arg) was performed as described previously (21). In this ELISA, an MAb is used with specificity for a neoantigenic determinant that is present on $\mathrm{C} 5 \mathrm{a} / \mathrm{C} 5 \mathrm{a}$ (des Arg) but not on the native precursor protein $\mathrm{C} 5$. In brief, wells of microtiter plates were coated with $100 \mu \mathrm{L}$ of anti-C $5 \mathrm{a} \mathrm{MAb} \mathrm{C17/5}(40 \mu \mathrm{g} / \mathrm{mL})$ in carbonate buffer. After blocking of nonspecific binding sites, $100-\mu \mathrm{L}$ samples were applied per well. Purified C5a or plasma samples that were diluted at least 2-fold in PBS-Tween-20 mM EDTA were allowed to bind to the solid phase for $2 \mathrm{~h}$ and were detected by adding, in sequence, the second biotinylated antiC5a MAb G25/2 (1 $\mu \mathrm{g} / \mathrm{mL}$ PBS-Tween $)$ and a 1000-fold dilution of streptavidin-peroxidase in PBS-Tween, both incubation steps lasting $1 \mathrm{~h}$. Incubation periods were stopped by repeated wash cycles with PBS-Tween. C5a determinations were carried out by the colorimetric analysis of peroxidase-mediated hydrolysis of 2

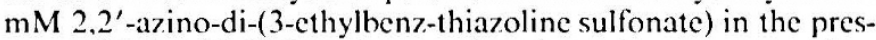
ence of $2.5 \mathrm{mM} \mathrm{H}_{2} \mathrm{O}_{2}$ using a microplate photometer, read at $410 \mathrm{~nm}$.

Alhumin assay: Albumin in plasma and tracheobronchial aspirate fluid was measured by single radial immunodiffusion (NOR-, VLC- and LC-partigen, Behring, Marburg, Germany).

Concentrations of constituents in lung effluent fluid. To avoid errors due to the sampling procedure, concentrations of constituents in tracheobronchial aspirate fluid are usually related to albumin concentrations. However, this is only correct when albumin concentrations in respiratory fluids are constant over a certain period of time. Because albumin concentrations were markedly affected by Dxm treatment, we chose to express concentrations of all constituents of lung effluent as weight unit $/ \mathrm{mL}$ of fluid. The suction technique was standardized as mentioned above. The recovered volume of pulmonary effluent by a single tracheal suction did not change in the week before and after Dxm treatment $(155 \pm 60$ versus $158 \pm 55 \mu \mathrm{L})$.

Analysis of $L / S$ ratio. Amniotic fluid or tracheal aspirates were obtained immediately after birth and frozen at $-30^{\circ} \mathrm{C}$. Analysis of $\mathrm{L} / \mathrm{S}$ ratio was done in modification as previously described (23).

Statistical analysis. Because of the skewed distribution of the results, data of $\mathrm{C} 5 \mathrm{a}$ measurements are expressed as median (25th-75th percentile) and analyzed for statistical significance using the Mann-Whitney $U$ test and the Wilcoxon signed-rank test, as appropriate. Clinical data are expressed as mean \pm SD and analyzed for statistical significance by means of the paired and unpaired $t$ test. A $p$ value $<0.05$ was considered statistically significant.

\section{RESULTS}

Patients. Birth weight and gestational age were slightly lower, but $\mathrm{L} / \mathrm{S}$ ratios were significantly lower in infants with high risk for CLD compared with controls (birth weight $881 \pm 169$ versus $928 \pm 126$ g. NS; gestational age $26.9 \pm 1.8$ versus $28.1 \pm 2.1$ wk, NS; L/S ratio $1.7 \pm 0.4$ versus $2.6 \pm 1.1, p<0.01$ ). There were no differences for birth weight, gestational age, or $\mathrm{L} / \mathrm{S}$ ratio between the early and late Dxm-treatment group. Thirteen infants of the CLD-risk group, who had been treated with Dxm. but only one infant of the control group eventually developed CLD defined as radiologic abnormalities and oxygen requirement on d 28.

C5a concentrations in lung effluent fluid. C5a/C5a(des Arg) levels at $\mathrm{d} 10$ were significantly higher in infants at risk for CLD compared with controls: 2.40 (1.13-3.38) versus $0.82(0.55-1.78)$ $\mu \mathrm{g} / \mathrm{L}, p<0.05$. After treatment with Dxm. C5a concentrations decreased both in the early treatment regimen initiated at $\mathrm{d} 10$ postnatal age $(p<0.01)$ and in the late treatment regimen begun at d $16(p<0.01)$ (Table 1). On d 15, the late-treated group served as the control group for therapy effects of the early treatment group. After Dxm administration. C5a concentrations decreased in the early treatment group compared with pretreatment values of the late treatment group $(p<0.01)$.

Albumin concentrations in lung effluent fluid. Compared with control infants, albumin concentrations were higher in CLD-risk infants $[0.25(0.17-0.39) \mu \mathrm{g} / \mathrm{L}$ versus $0.15(0.10-0.23) \mu \mathrm{g} / \mathrm{L}, p<$ $0.05]$. After therapy with Dxm, albumin concentrations significantly decreased in both the early and late treatment regimen [early treatment group, before Dxm: $0.28(0.10-0.39) \mathrm{g} / \mathrm{L}$; after Dxm: $0.06(0.03-0.11), p<0.01$; late treatment group, before Dxm: $0.26(0.21-0.38) \mathrm{g} / \mathrm{L}$; after Dxm: $0.09(0.06-0.26) \mathrm{g} / \mathrm{L} . p$ $<0.05]$.

Severity of illness variables. Ventilator settings of fraction of inspired oxygen and PIP that were necessary to obtain blood 
Table 1. Concentration of C5a/C5a(des Arg) in pulmonary effluent and severity of illness variables of infants with low risk for CLD (controls) and infants with high risk for CLD who have been treated with Dxim on d 10 (early treatment group) or d 16 (late treatment group)*

\begin{tabular}{|c|c|c|c|c|c|c|}
\hline & \multirow[b]{3}{*}{$\begin{array}{c}\text { Controls }(n=10) \\
(\mathrm{d} 10)\end{array}$} & \multicolumn{5}{|c|}{ Dxm } \\
\hline & & \multicolumn{2}{|c|}{ Early treatment group $(n=14)$} & \multicolumn{3}{|c|}{ Late treatment group $(n=13)$} \\
\hline & & $\begin{array}{c}\operatorname{Pre} \\
(\mathrm{d} 10)\end{array}$ & $\begin{array}{l}\text { Post } \\
\text { (d 15) }\end{array}$ & $\begin{array}{c}\text { Pre } \\
\text { (d 10) }\end{array}$ & $\begin{array}{l}\text { Pre } \\
\text { (d 15) }\end{array}$ & $\begin{array}{l}\text { Post } \\
\text { (d 20) }\end{array}$ \\
\hline $\begin{array}{l}\text { C5a/C5a(des Arg) concentration } \\
(\mu \mathrm{g} / \mathrm{L})\end{array}$ & $\begin{array}{c}0.82 \\
(0.55-1.78)\end{array}$ & $\begin{array}{c}2.73 \\
(1.22-3.38)\end{array}$ & $\begin{array}{c}0.57+7 \\
(0.18-1.02)\end{array}$ & $\begin{array}{c}2.22 \\
(1.09-3.66)\end{array}$ & $\begin{array}{c}2.22 \\
(0.98-3.92)\end{array}$ & $\begin{array}{c}0.56 \dagger \\
(0.15-0.91)\end{array}$ \\
\hline $\mathrm{FiO}_{2}$ & $0.23 \pm 0.03$ & $0.51 \pm 0.16$ & $0.25 \pm 0.04 t \ddagger$ & $0.47 \pm 0.13$ & $0.50 \pm 0.19$ & $0.29 \pm 0.09 \$$ \\
\hline $\operatorname{PIP}(k P a)$ & $1.19 \pm 0.15$ & $1.93 \pm 0.54$ & $1.34 \pm 0.30+\|$ & $1.81 \pm 0.22$ & $1.86 \pm 0.35$ & $1.42 \pm 0.21 \$$ \\
\hline
\end{tabular}

* Values represent median (25th-75th percentile) for C5a measurements, and mean \pm SD for clinical data. FiO ${ }_{2}$, fraction of inspired oxygen.

$\dagger p<0.01$, pre- is posttreatment within one group.

$\ddagger p<0.01$, early group, posttreatment is late group, pretreatment on d 15 between Dxm groups.

$\S p<0.05$, pre- is posttreatment within one group.

$\| p<0.05$, early group, posttreatment $w$ late group, pretreatment on $\mathrm{d} 15$ between Dxm groups.

gases within normal ranges are shown in Table 1. According to the inclusion criteria, they were higher in infants at risk for CLD compared with controls and decreased after both early and late Dxm treatment.

C5 a concentrations in plasma. In eight infants who had been treated with Dxm, quantitation of C5a in plasma was performed in parallel to determinations in lung effluent fluid. In contrast to levels in airway secretions [pre Dxm $1.97(1.11-2.22)$, post Dxm $0.52(0.17-0.86) \mu \mathrm{g} / \mathrm{L}, p<0.05]$. C5a concentrations in plasma were not affected by Dxm treatment [pre Dxm 3.38 (2.04-4.41) $\mu \mathrm{g} / \mathrm{L}$, post Dxm $4.62(1.65-5.80) \mu \mathrm{g} / \mathrm{L}$, difference not significant].

Lung effluent fluid/plasma ratio. Lung effluent/plasma ratio of albumin on d 10 was 0.012 [albumin in lung effluent: 0.26 $(0.12-0.35) \mathrm{g} / \mathrm{L}$; albumin in plasma: $21.9(16-24) \mathrm{g} / \mathrm{L}]$. The lung effluent/plasma ratio of $\mathrm{C} 5 \mathrm{a}$ was 0.59 .

\section{DISCUSSION}

In this study, we provide evidence that the complement component C5a may be involved in the recruitment of inflammatory cells into the airways of preterm infants during the development of CLD. C5a concentrations in pulmonary effluent of infants at risk for CLD were higher compared with control infants. After treatment with Dxm, C5a concentrations significantly decreased. These results correspond well with the neutrophil count in respiratory fluids of ventilated preterm infants. Infants who later developed CLD had increased numbers of neutrophils in lung effluent fluid compared with controls (1,2). After treatment with Dxm, neutrophil count in airway secretions was reduced (18). We have previously shown that infants at risk for CLD have high chemotactic activity of lung effluent fluid, and that this chemotactic activity was reduced after Dxm treatment (3). High chemotactic activity of airway fluids is a common feature of inflammatory lung diseases (24). Because C5a is a potent chemoattractant, it may considerably contribute to neutrophil influx into the airways. Additionally, C5a has marked effects on microvascular permeability (25). Whether C5a that is present in respiratory fluids alters lung permeability depends on where and how it is generated.

The source of C5a detectable in airway secretions is not clear. It may be of local or systemic origin. A systemic complement activation has been postulated for the pathogenesis of ARDS. In animal models, systemic activation can induce neutrophil accumulation in the lungs and an increased pulmonary epithelial permeability (26). However, only half of human patients with ARDS showed evidence for systemic complement activation, but nine of 10 patients had $\mathrm{C} 5 \mathrm{a}$ in the bronchoalveolar lavage fluid (9). Systemic activation of the complement system does not seem to be necessary for the observed pulmonary effects of C5a. Direct instillation of $\mathrm{C} 5 \mathrm{a}$ into the lungs of rabbits is also associated with a massive influx of neutrophils into the airways (27). Neutrophil pulmonary recruitment mediated by $\mathrm{C} 5$ a thus may occur via local activation of complement components. Although the liver is the major site of synthesis of complement proteins, components of both pathways are produced in lung tissue as well. C2, $\mathrm{C} 4$, and factor $\mathrm{B}$ have been found to be produced by macrophages $(28,29)$ and type II alveolar epithelial cells (29). Additionally, type II cells are capable of synthesizing of C3 and C5 (30). These factors secreted by cells of the alveolar wall are thought to contribute to local inflammatory responses in the lung. Neutrophils attracted by other chemotactic active material can cleave locally produced $\mathrm{C} 5$ to chemotactic $\mathrm{C} 5$ a by elastase release (31) and thus amplify the inflammatory response. Free elastase activity has been detected in pulmonary effluent already in the early stages of RDS (1, 32)

The complement system may also be activated by trauma in the immature lung. As shown in our patients, C5a levels are closely related to barotrauma, indicated by PIP and high oxygen concentrations. In preterm infants with surfactant deficiency, positive pressure ventilation rapidly initiates epithelial disruption of the airways (33). Hyperoxia also damages the pulmonary tissue. Trauma can induce complement activation via the contact and the kinin systems (34). Furthermore, exposure of complement components present in interstitial or airway-lining fluid to subcellular membrane fragments can lead to an activation of the cascade (35). When activated locally, C5a may considerably contribute to increased lung permeability, which has been shown to be associated with CLD (20).

$\mathrm{C} 5 \mathrm{a}$ is also detectable in plasma. In the blood of healthy individuals, there is a low-grade generation of C5a that is rapidly bound to white blood cells. C5a levels measured in plasma of our infants were comparable to those of healthy adults (21). Because lung microvascular permeability is increased in infants with CLD, high levels of C5a in lung effluent fluid thus may result from increased plasma leakage. This explanation would imply that $\mathrm{C} 5 \mathrm{a}$ is not the primary agent that alters lung permeability. The cause of the increased pulmonary microvascular permeability in CLD is not known, but it is thought to be due to an inflammatory process that is associated with the development of the disease (36). Mediators other than C5a with marked effects on microvascular permeability have been detected in the airways of infants with CLD and could be responsible for the increased permeability observed (37).

Our data show that $\mathrm{C} 5 \mathrm{a}$ concentrations in lung emluent fluid are significantly decreased after Dxm treatment. In contrast, C5a concentrations in plasma are not affected by Dxm. This finding may indicate that Dxm exerts different effects on the local 
complement system and the systemic cascade. It is not clear whether complement metabolism and serum levels are affected by glucocorticosteroids (38-41). However, in vitro formation of $\mathrm{C} 3 \mathrm{a}$ and $\mathrm{C} 5 \mathrm{a}$ has been shown to be inhibited by glucocorticosteroids $(41,42)$. Furthermore, there is evidence that locally produced complement components are affected. The administration of glucocorticosteroids to guinea pigs inhibited $\mathrm{C} 2$ and $\mathrm{C} 4$ biosynthesis by bronchoalveolar macrophages (43).

Dxm may act not on local C5a generation but on factors that are necessary for the C5a-mediated mechanisms. The increase of vascular permeability induced by $\mathrm{C} 5 \mathrm{a}$ is not due to a direct action on the endothelial cells but is caused by the interaction between endothelial cells and neutrophils. These effects are neutrophil dependent and are completely abolished by depletion of neutrophils (8). Dxm may act on agents that mediate this endothelial-neutrophil interaction. IL-1 induces endothelial expression of adhesion molecules, and Dxm effects on IL-1 production are well documented (44). Furthermore, vascular permeability is dependent on local blood flow (25). Effects of Dxm on local vasodilatatory prostaglandin synthesis (39) may also lead to a decreased C5a-mediated endothelial fluid leakage.

Dxm therapy has been shown to improve capillary integrity and thus to reduce pulmonary fluid leakage in infants with CLD $(3,18,20)$. Similar results were obtained in our patients, inasmuch as albumin concentrations were significantly decreased after Dxm treatment. Diminished levels of C5a in lung effluent fluid after Dxm therapy thus may be due to a decreased leakage from plasma, without any effect on local or systemic C5a generation. Effects of Dxm on other mediators that increase lung permeability have been described. The generation of leukotrienes (45) and of platelet-activating factor (46) are both affected by Dxm therapy.

In conclusion, this study shows that increased levels of C5a are present in the airways during the early development of CLD. Regardless if it is produced locally or derives from increased leakage from plasma, $\mathrm{C} 5 \mathrm{a}$ in pulmonary secretions may be capable of amplifying the inflammatory process by recruiting neutrophils and macrophages. However, currently we do not know whether increased concentrations of $\mathrm{C} 5 \mathrm{a}$ in airway fluids induce an increased pulmonary microvascular permeability or whether the presence of $\mathrm{C} 5 \mathrm{a}$ in respiratory secretions is a consequence of increased lung leakage. The inflammatory response is a complex reaction depending on a network of various humoral mediators and effector cells (25). Studies on the time-dependent generation and interaction of inflammatory mediators detectable in airway secretions of infants with CLD will further clarify the role of inflammation in the pathogenesis of this disease.

Acknowledgment. The authors thank G. Sonntag for her excellent technical assistance.

\section{REFERENCES}

I. Merritt TA, Stuard ID, Puccia J, Wood B, Edwards DK. Finkelstein J, Shapiro DL 1981 Newborn tracheal aspirate cytology: classification during respiratory distress syndrome and bronchopulmonary dysplasia. J Pediatr 98:949956

2. Ogden B, Murphy S, Saunders G, Pathak D, Johnson J 1984 Neonatal lung neutrophils and elastase/proteinase inhibitor imbalance. Am Rev Respir Dis 130:817-821

3. Groneck P, Reuss D, Götze-Speer B, Speer CP 1993 Effects of dexamethasone on chemotactic activity and inflammatory mediators in tracheobronchial aspirates of preterm infants at risk for chronic lung disease. J Pediatr 122:938-944

4. Tate RM, Repine JE 1983 Neutrophils and the adult respiratory distress syndrome. Am Rev Respir Dis 128:552-559

5. Merritt TA, Cochrane CG, Holcomb K, Bohl B, Hallman M, Strayer D. Edwards DK, Gluck L 1983 Elastase and $\alpha_{1}$-proteinase inhibitor activity in tracheal aspirates during respiratory distress syndrome. J Clin Invest 72:656662

6. Shasby DM, Vanbenthuysen KM. Tate RM, Shasby SS. McMurty I, Repine JE 1982 Granulocytes mediate acute edematous lung injury in rabbits and in isolated rabbit lungs perfused with phorbol myristat: role of oxygen radicals. Am Rev Respir Dis 125:443-447

7. Saugstadt O, Buo L, Johansen HT, Roise O. Aasen A 1992 Activation of the plasma kallikrein-kinin system in respiratory distress syndrome. Pediatr Res 32:431-435

8. Goldstein IM 1988 Complement: biologically active products. In: Gallin JI. Goldstein IM, Snyderman R (eds) Inflammation. Basic Principles and Clinical Correlates. Raven Press, New York, pp 55-67

9. Robbins RA, Russ WD, Rasmussen JK. Clayton MM 1987 Activation of the complement system in the adult respiratory distress syndrome. Am Rev Respir Dis 135:651-658

10. Hopkins H. Stull T, von Essen SG. Robbins RA. Rennard SI 1989 Neutrophil chemotactic factors in bacterial pneumonia. Chest 95:1021-1027

11. Fick RB, Robbins RA, Squier SU, Schoderbek WE, Russ WD 1986 Complement activation in cystic fibrosis respiratory fluids: in vivo and in vitro generation of C5a and chemotactic activity. Pediatr Res 20:1258-1268

12. Mammel MC. Green TP. Johnson DA. Thompson TR 1983 Controlled trial of dexamethasone therapy in infants with bronchopulmonary dysplasia. Lancet 1:1356-1358

13. Avery GB, Fletcher AB, Kaplan M, Brudno S 1984 Controlled trial of dexamethasone in respirator-dependent infants with bronchopulmonary dysplasia. Pediatrics 75:106-111

14. Barrington K. Finer NN 1985 Evaluation of the efficacy of dexamethasone in prevention of severe bronchopulmonary dysplasia. J Perinatol 5:26-32

15. Cummings JJ, D'Eugenio DB, Grooss SJ 1989 A controlled trial of dexamethasone in preterm infants at high risk for bronchopulmonary dysplasia. $\mathrm{N}$ Engl J Med 320:1505-1510

16. Harkavy KL, Scanlon JW, Chowdhry PK. Grylack LJ 1989 Dexamethasone therapy in ventilator-and oxygen dependent infants: a controlled study. J Pediatr 115:979-983

17. Collaborative Dexamethasone Trial Group 1991 Dexamethasone in neonatal chronic lung disease: an international placebo-controlled trial. Pediatrics $88: 421-427$

18. Yoder MC, Chua R. Tepper R 1991 Effect of dexamethasone on pulmonary inflammation and pulmonary function of ventilator-dependent infants with bronchopulmonary dysplasia. Am Rev Respir Dis 143:1044-1048

19. Gerdes JS, Harris MC, Polin RA 1988 Effects of dexamethasone and indomethacin on elastase, $\alpha_{1}$-proteinase inhibitor, and fibronectin in bronchoalveolar lavage fluid from neonates. J Pediatr 113:732-737

20. Watts CL. Bruce MC 1992 Effect of dexamethasone on fibronectin and albumin levels in lung secretions of infants with bronchopulmonary dysplasia. J Pediatr 121:597-607

21. Oppermann M, Schulze M, Goetze O 1991 A sensitive enzyme immunoassay for the quantitation of human C 5a/C Sa(des Arg) anaphylatoxin using a monoclonal antibody with specificity for a neoepitope. Complement Inflamm 8:13-24

22. Speer CP, Rohertson B, Cursted T, Halliday H, Compagnone D, Gefeller O. Harms K. Herting E, McClure G, Reid M, Tubman R, Herin P, Noack G. Kok J, Koppe J, van Sonderen L, Laufkötter E, Köhler W. Bochnisch H, Albrecht K, Hanssler L, Haim M, Oetomo S, Okken A, Altfeld P. Groneck P. Kachel W. Relier J, Walti H 1992 Randomized European multicenter trial of surfactant therapy for severe neonatal respiratory distress syndrome: single versus multiple doses of Curosurf. Pediatrics 89:13-20

23. Gluck L. Kulovich MV 1973 Lecitin/sphingomyelin ratios in amniotic fluid in normal and abnormal pregnancy. Am J Obstet Gynecol 115:539-546

24. Reynolds IIY 1983 Lung inflammation: role of endogenous chemotactic factors in attracting polymorphonuclear granulocytes. Am Rev Respir Dis 127:S16-S25

25. Movat $\mathrm{ZH} 1984$ The Inflammatory Reaction. Elsevier. Amsterdam

26. Till GO, Johnson KJ, Kunkel R, Ward PA 1982 Intravascular activation of complement and acute lung injury. J Clin Invest 69:1126-1!35

27. Henson PM, McCarthy K. Larsen GL. Webster O, Giclas PC, Dreisin RB. King TE, Shaw JO 1979 Complement fragments, alveolar macrophages, and alveolitis. Am J Pathol 97:93-110

28. Cole FS, Matthews WJ, Rossing TH, Gash DJ, Lichtenberg NA, Pennington JE 1983 Complement biosynthesis by human bronchoalveolar macrophages. Clin Immunol Immunopathol 27:153-159

29. Strunk RC, Eidlen DM, Mason RJ 1988 Pulmonary alveolar type II epithelial cells synthesize and secrete proteins of the classical and alternative complement pathways. J Clin Invest 81:1419-1426

30. Rothmann BL. Merrow M. Bamba M. Kennedy T. Kreuzer D 1989 Biosynthesis of the third and fifth complement component by isolated human lung cells. Am Rev Respir Dis 139:212-220

31. Janoff A 1985 Elastase in tissue injury. Annu Rev Med 36:207-216

32. Speer CP, Reuss D, Harms K, Herting E. Gefeller O 1993 Neutrophil elastase and acute pulmonary damage in infants with severe respiratory distress syndrome. Pediatrics $91: 794-799$

33. Robertson B 1989 The evolution of neonatal respiratory distress syndrome into chronic lung disease. Eur Respir J 2(suppl 3):33s-37s

34. Clark RAF 1988 General considerations of wound repair. In: Clark RAF, Henson PM (eds) The Molecular and Cell Biology of Wound Repair. Plenum Press, New York, pp 3-33

35. Giclas PC, Pinckard RN, Olson MS 1979 In vitro activation of complement by isolated human heart subcellular membranes. J Immunol 122:146-151

36. O'Brodovich HM, Mellins RB 1985 Bronchopulmonary dysplasia. Unresolved neonatal lung injury. Am Rev Respir Dis 132:694-709

37. Stenmark KR, Eyzaguirre M, Westcott JY, Henson PM, Murphy RC 1987 Potential role of eicosanoids and PAF in the pathophysiology of bronchopulmonary dysplasia. Am Rev Respir Dis 136:770-772 
38. Atkinson JP. Frank MM 1973 Effect of cortisone therapy on serum complement components. J Immunol 111:1061-1066

39. Bowen DL, Fauci AS 1988 Adrenal corticosteroids In: Gallin JI, Goldstein IM, Snyderman R (eds) Inflammation, Basic Principles and Clinical Correlates. Raven Press, New York, pp 877-896

40. Claman HN 1974 How corticosteroids work. J Allerg Clin Immun 55:14515

41. Bengtson A. Heideman M 1988 Anaphylatoxin formation in sepsis. Arch Surg 123:645-649

42. Weiler JM, Packard BP 1982 Methylprednisolone inhibits the alternative and amplification pathways of complement. Infect Immun 38:122-126
43. Pennington JE. Matthews WJ, Marino JT. Colten HR 1979 Cyclophosphamide and cortisone acetat inhibit complement biosynthesis by guinea pig bronchoalveolar macrophages. J Immunol 123:1318-1321

44. Bochner BS, Rudledge BK, Schleimer RP 1987 Interleukin-1 production by human lung tissue. II. Inhibition by anti-inflammatory steroids. J Immunol 139:2303-2307

45. Tsurufuji S, Kurihara A. Kiso S, Suzuki Y, Ohuchi K 1984 Dexamethasone inhibits generation in inflammatory sites of the chemotactic activity attributable to leukotriene B. Biochem Biophys Res Commun 119:884-890

46. Boschetto P, Rogers DF, Fabbri LM, Barnes PJ 1991 Corticosteroid inhibition of airway microvascular leakage. Am Rev Respir Dis 143:605-609 